\title{
Identification of volatile and semi-volatile compounds produced by Tenebrio molitor larvae
}

\author{
Aleksandra Bojke ${ }^{1}$, Cezary Tkaczuk², Piotr Stepnowski³, Marek Gołębiowski ${ }^{1}$ \\ ${ }^{1}$ Laboratory of Analysis of Natural Compounds, Department of Environmental Analysis, Faculty of Chemistry, University of Gdańsk, Wita Stwosza 63 \\ Gdańsk, Poland \\ ${ }^{2}$ Department of Plant Protection and Breeding, Faculty of Natural Sciences, Siedlce University of Natural Sciences and Humanities, Prusa 14, Siedlce, \\ Poland \\ ${ }^{3}$ Laboratory of Chemical Environmental Risks, Department of Environmental Analysis, Faculty of Chemistry, University of Gdańsk, Wita Stwosza 63, Gdańsk, \\ Poland \\ Corresponding author: aleksandra.ostachowska@phdstud.ug.edu.pl
}

DOI: 10.31708/spi3.2018/boj.cns18

\section{Introduction}

The following research concerns issues related to beetles (Coleoptera), which is one of the most numerous rows of insects. Beetles inhabit a diverse environment. There are land species as well as those found in freshwater. These are both herbivorous and predatory animals, scavengers and omnivores. Tenebrio molitor is one of the largest beetles. Larvae typically measure about $3 \mathrm{~cm}$ or more, whereas adults are generally between 1.25 and $1.8 \mathrm{~cm}$ in length. Tenebrio molitor go through four life stages: eggs, larvae, pupae, and adults (Rho \& Lee, 2016). This pest is most common in mills, bakeries, warehouses and feed storage rooms. Tenebrio molitor harms not only by eating products but also by contaminating them with droppings (Wiśniowski, 1977). Bearing in mind that the contact with insects in the environment is an inevitable, and the disposal of the species causing economic damages is very difficult. Attempts have been made to get to know the compounds produced by insects. We therefore decided to check the quality of volatile and semi-volatile compounds produced by Tenebrio molitor. The results will also help expand the knowledge about insect pathology.

\section{Materials and Methods}

Tenebrio molitor used in the study were obtained from the Collection of the Department of Plant Protection and Breeding, Siedlce University of Natural Sciences and Humanities (Siedlce, Poland). A culture of the beetle larvae T. molitor was maintained and reared in temperature- and humidity-controlled chambers $\left(30^{\circ} \mathrm{C}, 70 \%\right.$ relative humidity). A method of the analysis of volatile compounds was developed using DVB/CAR/PDMS fiber (polydimethylsiloxane/carboxen/ divinylbenzene). The GC-MS analysis was conducted using a GCMS-QP2010SE Shimadzu System (Shimadzu, Kyoto, Japan). The identification of compounds was made based on the mass spectral libraries and literature data.

\section{Results}

Analysis of results of HS-SPME / GC-MS revealed the presence of 26 compounds, among which were following groups such as: acids (10), aldehydes (10) and other compounds (6). The last group includes: alkanes (3), esters (1), amine (1) and phenol (1). It can be observed that larvae produce much more aldehydes compared to alkanes. Methyl esters did not occur in insects. In larvae $T$. molitor were found saturated and unsaturated fatty acids. The acids in the mixture may be responsible for defensive functions in insects. In order to confirm this thesis further microbiological tests are required, which are planned to be conducted in the near future.

\section{Discussion}

The main components produced by insects are: hydrocarbons, esters, ketones, aldehydes, ketones, alcohols, triacylglierols and fatty acids (Lease \& Wolf, 2011; M.Th. Beenakkers, Van der Horst, \& Van Marrewijk, 1985). The HS-SPME technique in combination with GC-MS enabled the detection of these compounds. It was used to analyze, among others: Bagrada hilaris and Tribolium castaneum (Theodoridis, Koster, \& de Jong, 2000; Villaverde, Juárez, \& Mijailovsky, 2007). That's why this technique was chosen for $T$. molitor analysis. Many publications indicate mainly the occurrence of fatty acids and hydrocarbons. Research carried out as part of this work confirms this relationship.

\section{Acknowledgements}

The project was funded by the National Science Centre (NCN) conferred on the basis of the decision number 2016/21/N/NZ4/03613.

\section{References}

Lease, H. M. \& Wolf, B. O. (2011). Lipid content of terrestrial arthropods in relation to body size, phylogeny, ontogeny and sex. Physiological 
Entomology, 36(1), 29-38.

https://doi.org/10.1111/j.1365-3032.2010.00767.x

M.Th. Beenakkers, A., Van der Horst, D. J., \& Van Marrewijk, W. J. A. (1985). Insect lipids and lipoproteins, and their role in physiological processes. Progress in Lipid Research, 24(1), 1967. https://doi.org/10.1016/0163-7827(85)90007-4

Rho, M. S. \& Lee, K. P. (2016). Balanced intake of protein and carbohydrate maximizes lifetime reproductive success in the mealworm beetle, Tenebrio molitor (Coleoptera: Tenebrionidae). Journal of Insect Physiology, 91-92, 93-99. https://doi.org/10.1016/j.jinsphys.2016.07.002

Theodoridis, G., Koster, E. H. \& de Jong, G. (2000). Solid-phase microextraction for the analysis of biological samples. Journal of Chromatography B: Biomedical Sciences and Applications, 745(1), 49-82. https://doi.org/10.1016/S03784347(00)00203-6

Villaverde, M. L., Juárez, M. P. \& Mijailovsky, S. (2007). Detection of Tribolium castaneum (Herbst) volatile defensive secretions by solid phase microextraction-capillary gas chromatography (SPME-CGC). Journal of Stored Products Research, 43(4), 540-545.

https://doi.org/10.1016/j.jspr.2007.03.003

Wiśniowski, K. (1977). Towaroznawstwo artykułów spożywczych. Warszawa: Wydawnictwo Szkolne i Pedagogiczne. 